\title{
The pulmonary and autonomic effects of high-intensity and low-intensity exercise in diesel exhaust
}

\author{
Luisa V. Giles ${ }^{1,2^{*}}$, Christopher Carlsten ${ }^{3,4,5}$ and Michael S. Koehle $2,6,7$
}

\begin{abstract}
Background: Exposure to air pollution impairs aspects of pulmonary and autonomic function and causes pulmonary inflammation. However, how exercising in air pollution affects these indices is poorly understood. Therefore, the purpose of this study was to determine the effects of low-intensity and high-intensity cycling with diesel exhaust (DE) exposure on pulmonary function, heart rate variability (HRV), fraction of exhaled nitric oxide (FeNO), norepinephrine and symptoms.

Methods: Eighteen males performed 30-min trials of low-intensity or high-intensity cycling (30 and 60\% of power at $\mathrm{VO}_{2 \text { peak }}$ ) or a resting control condition. For each subject, each trial was performed once breathing filtered air (FA) and once breathing DE (300 $\mathrm{\mu g} / \mathrm{m}^{3}$ of $\mathrm{PM}_{2.5}$, six trials in total). Pulmonary function, FeNO, HRV, norepinephrine and symptoms were measured prior to, immediately post, $1 \mathrm{~h}$ and $2 \mathrm{~h}$ post-exposure. Data were analyzed using repeated-measures ANOVA.
\end{abstract}

Results: Throat and chest symptoms were significantly greater immediately following DE exposure than following FA $(p<0.05)$. FeNO significantly increased $1 \mathrm{~h}$ following high-intensity exercise in DE (21.9 (2.4) vs. 19.3 (2.2) ppb) and FA (22.7 (1.7) vs. 19.9 (1.4)); however, there were no differences between the exposure conditions. All HRV indices significantly decreased following high-intensity exercise $(p<0.05)$ in DE and FA. The exception to this pattern was LF (nu) and LF/HF ratio, which significantly increased following high-intensity exercise $(p<0.05)$. Plasma norepinephrine (NE) significantly increased following high-intensity exercise in DE and FA, and this increase was greater than following rest and low-intensity exercise $(p<0.05)$. DE exposure did not modify any effects of exercise intensity on HRV or norepinephrine.

Conclusions: Healthy individuals may not experience greater acute pulmonary and autonomic effects from exercising in DE compared to FA; therefore, it is unclear if such individuals will benefit from reducing vigorous activity on days with high concentrations on particulate matter.

Keywords: Air pollution, Exercise, Pulmonary function, FeNO, Norepinephrine, Exercise intensity

\section{Background}

In healthy individuals, exercise causes bronchodilation [1] and decreases the fraction of exhaled nitric oxide (FeNO), which is a surrogate measure of pulmonary inflammation [2]. In contrast, air pollution exposure that deposits particulate matter $(\mathrm{PM})$ in the respiratory tree results in

\footnotetext{
*Correspondence: gilesl@douglascollege.ca

${ }^{1}$ Sport Science Department, Douglas College, 700 Royal Ave, New

Westminster, BC V3M 5Z5, Canada

${ }^{2}$ School of Kinesiology, University of British Columbia, Vancouver, British

Columbia, Canada

Full list of author information is available at the end of the article
}

pulmonary oxidative stress and an increase in bronchial responsiveness, airway resistance, and airway inflammatory cells $[3,4]$. In susceptible populations [5], and some healthy populations [6] such physiological changes due to air pollution exposure can impair pulmonary function. Despite the opposing effects of exercise alone and air pollution exposure alone on pulmonary function and pulmonary inflammation, it is unclear how exercise modifies the pulmonary effects of air pollution.

Exposure to PM can also perturb the autonomic nervous system, resulting in an increase in sympathetic,

(C) The Author(s). 2018 Open Access This article is distributed under the terms of the Creative Commons Attribution 4.0 International License (http://creativecommons.org/licenses/by/4.0/), which permits unrestricted use, distribution, and 
and a decrease in parasympathetic nervous system activity [7], with a concomitant increase in norepinephrine levels in the paraventricular nucleus of the hypothalamus [8]. At the onset of physical activity, parasympathetic activity decreases [9-15], which likely represents the vagal withdrawal that occurs with physical activity or exercise [16]. Following exercise, perturbations in autonomic control return close to resting levels within $1 \mathrm{~h}$ [17]. Diesel exhaust (DE) contains PM and exposure to DE prior to exercise increases exercise heart rate and attenuates exercise-induced bronchodilation [1]. Therefore, it is possible that exposure to DE containing PM during exercise could affect autonomic and pulmonary function. However, there are no studies examining how the effects of DE on the autonomic nervous system are modified by exercise. Additionally, the studies directly examining the effects of continuous exercise with exposure to PM on pulmonary function, have led to inconsistent findings [18-20]. As exercise protocol, duration, and air pollution exposure characteristics vary, drawing any robust conclusions on how exposure to air pollution during exercise affects pulmonary function or inflammation is difficult.

When exercise intensity increases, minute ventilation increases and the proportion of PM that deposits in the respiratory tree increases [21-23], leading to a theoretical increase in the dose of diesel exhaust particulate matter (DPM). Therefore, one might expect that the magnitude of physiological and health effects of air pollution would be greater than during rest or lower intensity exercise. Therefore, the purpose of this study was to determine the effects of low- and high-intensity cycling on pulmonary function, pulmonary inflammation, autonomic function and symptoms of the throat/chest, nose and eyes. We hypothesized that exposure to DE would impair pulmonary function, increase the FeNO, plasma norepinephrine, and subjective symptoms and alter autonomic nervous system function (as measured by heart rate variability (HRV)). We also hypothesized that any physiological effects of DE would be magnified as exercise intensity increases.

\section{Methods}

Eighteen recreationally active males volunteered for the study. Participants were considered recreationally active and included in the study if they met Canada's physical activity guidelines of $150 \mathrm{~min}$ of moderate-to-vigorous activity per week. Only males were studied because FeNO is affected by sex hormones [24] that vary across the menstrual cycle; given that the study required participants to attend on seven occasions, testing in females would have needed to have occurred over a 7-month period, during which time activity levels and physiological parameters could vary significantly leading to an increase in variability of the data. Each participant was a non-smoker and had no history of respiratory or cardiovascular disease. The Clinical Research Ethics Board at the University of British Columbia approved this study. Participants attended an orientation session followed by a reflection period before signing the written informed consent. Prior to all visits, participants were asked to refrain from exhaustive exercise and alcohol for $24 \mathrm{~h}$, caffeine for $6 \mathrm{~h}$, and food or non-water beverages for $2 \mathrm{~h}$. Each participant performed all trials at the same time of day. Participants were also asked to maintain the same pre-test routine including the same mode of travel to the laboratory and pre-test meal, and were asked to refrain from vitamin supplementation for the duration of the study. The sample size was calculated based on a minimal detectable difference in FeNO of $2 \mathrm{ppb}$ [25], using an effect size of 0.37 (Cohen's $d$ ), a power of 0.8 , and an alpha of 0.05 .

\section{Experimental design}

Data collection for this study occurred as part of a larger study and overall methods are explained in detail in other publications [26, 27]. Briefly, each participant attended the laboratory on seven occasions and the initial visit served for familiarization and maximal exercise testing. On the remaining testing days, participants performed 30-min trials of low-intensity cycling, high-intensity cycling, or rest. Each intensity, including rest, was performed once in filtered air (FA) and once in DE with a target concentration of $300 \mu \mathrm{g} / \mathrm{m}^{3}$ of $\mathrm{PM}_{2.5}$, for a total of six trials, each of which was separated by a 7-day period. Exercise intensity and the exposure (FA and DE) were randomized with both the participant and the researcher blinded to the exposure condition and data suggests that individuals cannot determine whether they are exposed to DE or FA [28].

\section{Introductory session (day 1)}

For the maximal exercise test, the cycling work rate started at $100 \mathrm{~W}$ and increased by $0.5 \mathrm{~W} / \mathrm{s}$ until volitional exhaustion. To exclude those subjects with possible exercise-induced bronchoconstriction, any individual with a post-exercise decrease in forced expiratory volume in $1 \mathrm{~s}$ $\left(\mathrm{FEV}_{1}\right)$ by $10 \%$ or greater was excluded from the study.

\section{Testing visits (days 2-7)}

Testing visits 2-7 consisted of $30 \mathrm{~min}$ trials of cycling or 30 min of rest. Work rates on cycling days were based on the peak power achieved during the maximal exercise test. Low-intensity cycling was set at $30 \%$ of the power at $\dot{V} \mathrm{O}_{2 \text { peak }}(96.1(17.7) \mathrm{W})$ and high-intensity cycling was set at $60 \%$ of power at $\dot{V} \mathrm{O}_{2 \text { peak }}(192.2(35.3) \mathrm{W})$, which represented 48 and $77 \%$ of $\dot{V} \mathrm{O}_{2 \text { peak }}$ for low- and high-intensity cycling respectively. Control exposures involved sitting for 
the same period (30 min), but without performing exercise. Pulmonary function, FeNO, heart rate variability (HRV), plasma norepinephrine and symptoms were measured prior to, immediately post, $1 \mathrm{~h}$, and $2 \mathrm{~h}$ post-exposure. During the post exercise/exposure period participants were in a laboratory with normal environmental conditions.

\section{Exercise apparatus}

Exercise tests were performed using a Velotron cycle ergometer (Racermate Inc., Seattle, WA, USA). During trials, participants breathed through a facemask (7450 Series, Hans Rudolph Inc., Kansas City, MO, USA) attached to a low-resistance, non-rebreathing valve (NRB 2700, Hans Rudolph Inc., Kansas City, MO, USA). Participants remained outside the environmental booth but were connected to the booth via $3.2 \mathrm{~cm}$ diameter hoses at both the inspired and expired sides of the non-rebreathing valve.

\section{Outcome measures}

\section{Heart rate variability}

Following $20 \mathrm{~min}$ of supine rest, heart rate was recorded for five min in 15 participants in a quiet, dark room (Polar S810, Polar Electro, Finland). Heart rate variability was analyzed offline using custom software (Kubios HRV, Kuopio, Finland). Time domain measures included the standard deviation of normal-to-normal (NN) intervals $(\mathrm{SDNN})$, the root mean square of the mean differences in successive N-N intervals (RMSSD), and the HRV triangular index. Frequency domain analysis was performed using autoregressive modelling to determine the spectral powers at low frequency (LF: 0.04-0.15 $\mathrm{Hz}$ ) and high frequency (HF: $0.15-0.40 \mathrm{~Hz}$ ) as well as total power. Additionally, LF normalized units (LFnu), HF normalized units (HFnu), and LF/HF ratios were determined. Of the 360 measures of HRV taken, seven were excluded due to a poor signal. To prevent complete exclusion of those subjects with missing measurements and based on the recommendations of a statistician, the missing values were imputed using regression [29].

\section{FeNO}

The FeNO was measured with a NIOX $\mathrm{MINO}^{\circledR}$ Airway Inflammation Monitor (Aerocrine, Solna, Sweden), which detects exhaled NO as an indicator of inflammation. Measurements were performed as per the American Thoracic Society guidelines [30]. Briefly, subjects inhaled to close to total lung capacity and then exhaled at a flow rate of $50 \mathrm{ml} / \mathrm{s}$ and a pressure of $10 \mathrm{~cm} \mathrm{H}_{2} \mathrm{O}$ into the device for $6 \mathrm{~s}$. The device collected the expired gas from the last $3 \mathrm{~s}$ of the exhalation to determine the concentration of exhaled NO.

\section{Pulmonary function}

Pulmonary function was measured in 17 participants using a portable spirometer (Spirobank G, Medical International Research, Rome, Italy), as per the guidelines of the American Thoracic Society [31]. Standard indices of pulmonary function such as forced vital capacity (FVC), $\mathrm{FEV}_{1}$, ratio of FVC to $\mathrm{FEV}_{1}$ (FEV $\left.1 / \mathrm{FVC}\right)$, forced expiratory flow during the mid-portion (25-75\%) of an FVC $\left(\mathrm{FEF}_{25-75}\right)$ and peak expiratory flow rate (PEFR) were measured. Participants performed three manoeuvres (and up to a maximum of 6 , if necessary) per testing time point. For repeatability to be achieved, the difference between the highest and second highest trial for $\mathrm{FEV}_{1}$ and $\mathrm{FVC}$ was required to fall within $0.15 \mathrm{~L}$. The peak value for each variable was used for analysis.

\section{Plasma norepinephrine}

Blood samples were taken from the right antecubital fossa with a 21-gauge needle into vacutainers containing EDTA. All blood samples were immediately centrifuged at $1500 \mathrm{~g}$ for $20 \mathrm{~min}$ to separate plasma from formed elements. Plasma was extracted, frozen, and stored at $-80{ }^{\circ} \mathrm{C}$ until assayed. Plasma concentrations of norepinephrine were determined using commercially available enzyme-linked immunosorbent assay (ELISA) kits (Norepinephrine ELISA kit, Abnova, CA, USA) and according to the procedures outlined by the manufacturer. Plasma levels of norepinephrine were measured using a Versa Max microplate reader (Molecular Devices Corporation, CA, USA). The intra assay coefficient of variation for norepinephrine was $7.1 \%$.

Levels of norepinephrine were adjusted for changes in plasma volume from baseline. The estimated post-exercise concentration of markers due to plasma volume changes alone was estimated using the following equation [32]:

$$
\text { Concentration }_{\text {ESTIMATED }}=\frac{\text { Hct }_{\text {POST }} \times\left(100-\text { Hct }_{P R E}\right)}{\text { Hct }_{P R E} \times\left(100-H c t_{P O S T}\right)} \times \text { Concentration }_{P R E}
$$

where Hct represents hematocrit. The adjusted concentration was then calculated using the following equation:

$$
\begin{aligned}
\text { Concentration }_{A D J U S T E D}= & \left(\text { Concentration }_{P R E}-\text { Concentration }_{\text {ESTIMATED })}\right. \\
& + \text { Concentration }_{M E A S U R E D}
\end{aligned}
$$

\section{Symptoms}

At each time point, participants were asked to rate symptoms on a scale of $0-5$ with 0 being "no symptoms" and 5 being "severe". Participants were blinded to scores from previous time points and test days. Symptoms were grouped into eyes, nose, throat/chest and other and included the following questions: 
Eye symptoms: Are your eyes itchy? Are your eyes watering? Do you feel a painful or stinging sensation in your eyes?

Nasal symptoms: Does your nose feel itchy? Do you feel a painful or stinging sensation in your nose? Is your nose running? Is your nose blocked? Are you sneezing?

Throat/Chest symptoms: Does your throat feel dry, scratchy, or sore? Are you wheezing or do you have any whistling sounds in your chest? Are you having any chest pain? Are you having chest tightness? Do you have shortness of breath?

Other symptoms: Do you have a headache? Do you feel fatigued? Do you feel nauseous?

Within each category scores from individual questions were summed to provide a score for nasal, eyes, throat/ chest and other. The symptoms chosen were those typically reported in similar studies which demonstrate that participants are unable to determine if they are exposed to DE or FA [28].

\section{Exposure setup}

All exposures were performed using an environmental exposure booth that is explained in detail elsewhere [33], but modified only in that load was constant at $2.5 \mathrm{~kW}$. For DE exposures, participants were exposed to calibrated, aged, and diluted DE that had a target concentration of $300 \mu \mathrm{g} / \mathrm{m}^{3}$ of $\mathrm{PM}_{2.5}$. In-booth PM mass concentration measurements were made using a Tapered Element Oscillating Microbalance (TEOM; Model 1400a, Rupprecht \& Pattashnick, Albany, NY, USA) using 10 min averages. A TSI Scanning Mobility Particle Scanner (Model 3936, TSI, Shoreview, MN, USA) classified the particle size distribution between $2.5 \mathrm{~nm}$ and $1000 \mathrm{~nm}$. For FA exposures, participants were exposed to compressed, HEPA-filtered air.

\section{Statistical analysis}

Statistical analyses were completed using SPSS software (SPSS Inc., version 20, Chicago, IL) and analyses were chosen through consultation with a $\mathrm{PhD}$ statistician. For each parameter, data were analyzed using a 2 (exposure: FA vs. DE) $\times 3$ (intensity: rest, low-intensity, high-intensity) $\times 4$ (time: pre, post, $1 \mathrm{~h}, 2 \mathrm{~h}$ ) repeated measures ANOVA. Significance was set at $p<0.05$. Main or interaction effects were further analyzed using pair-wise comparisons and significance was adjusted to account for multiple comparisons using the Sidak adjustment. The $p$-values represented in this manuscript have been inflated to incorporate the Sidak adjustment, meaning that $\alpha$ remains at 0.05. Specifically, the Sidak adjustment uses the following equation to adjust for multiple comparisons: 1 - (1-unadjusted $p$-value $)^{1 / \mathrm{k}}$, where $\mathrm{k}$ is the number of comparisons in the family. For the post-hoc analysis comparing exercise intensity, $p$-values were adjusted for 3 groups (rest, low-intensity and high-intensity) and when time was compared, $p$-values were adjusted for 4 groups (pre, post, $1 \mathrm{~h}, 2 \mathrm{~h}$ ). All means are reported with standard deviations in parentheses.

\section{Results}

Eighteen recreationally active males (age 24.5 (6.2) yr. (mean (sd)); height: 1.78 (0.08) m; body mass: 74.2 (10.5) kg) completed the study. Their mean $\dot{V} \dot{O}_{2 \text { peak }}$ was 55.0 (9.1) $\mathrm{mL} \cdot \mathrm{kg}^{-1} \cdot \mathrm{min}^{-1}$, participants had a mean maximum power output was 320.4 (58.9) W, and mean maximum heart rate was 182.1 (12.7) bpm.

Baseline outcome variables were not significantly different across the six test days $(p>0.05)$. All participants performed all six trials, although three participants were unable to finish the high-intensity trial in DE due to volitional exhaustion. In individuals who were unable to finish the first high-intensity trial, the second high-intensity exercise trial was designed to mimic the first; therefore, the duration in trial two was reduced to match the first trial. Exposure to $\mathrm{PM}_{2.5}$ was 9.3 (6.20) and 302.1 (6.50) $\mu \mathrm{g} / \mathrm{m}^{3}$ for FA and DE respectively. Mean particle number concentration (PNC) during FA and DE exposures were $0.14 \times 10^{4}$ and $61.60 \times 10^{4}\left(\# / \mathrm{cm}^{3}\right)$. Mean $\mathrm{NO}_{2}$ during $\mathrm{FA}$ and DE exposures was 0.04 (0.04) and $0.58(0.15) \mathrm{ppm}$. Mean NO during FA and DE exposures was $0.02(0.02)$ and $7.00(0.09)$ ppm. Mean carbon monoxide during FA and DE exposures was $3.00(0.40)$ and 13.9 (2.10) ppm.

There was a significant intensity-by-time interaction for all time and frequency domain indices of HRV $(p<0.05)$. All indices except LF $(\mathrm{nu})$ and LF/HF ratio significantly decreased following high-intensity exercise. Immediately post and $1 \mathrm{~h}$ post-exposure, these variables were significantly lower following high-intensity exercise compared to following rest. Conversely, compared to baseline and to rest, LF (nu) and LF/HF ratio significantly increased following high-intensity exercise (Fig. 1). For detailed comparisons of significant differences see Additional files 1 and 2. There were no effects of exposure condition on any indices of HRV.

There was a significant three-way interaction for FeNO (exposure-by-intensity-by-time; $p=0.045$, Fig. 2). Immediately following rest in FA, FeNO was significantly greater than at $1 \mathrm{~h}$ post exposure (Fig. 2a. $p=0.025 ; 21.3(2.2)$ ppb vs. 19.6 (2.0) ppb). One hour following high-intensity exercise in DE, FeNO was significantly greater than pre-exercise (Fig. 2c. $p=0.024 ; 21.9$ (2.4) ppb, vs. $19.3(2.2) \mathrm{ppb})$. Prior to high intensity exercise in FA, FeNO was significantly less than immediately post exposure (Fig. 2c. $p=0.048 ; 19.9$ (1.4) ppb, vs. 22.7 (1.7) ppb); however, there were no differences between FA and DE for any comparisons. 

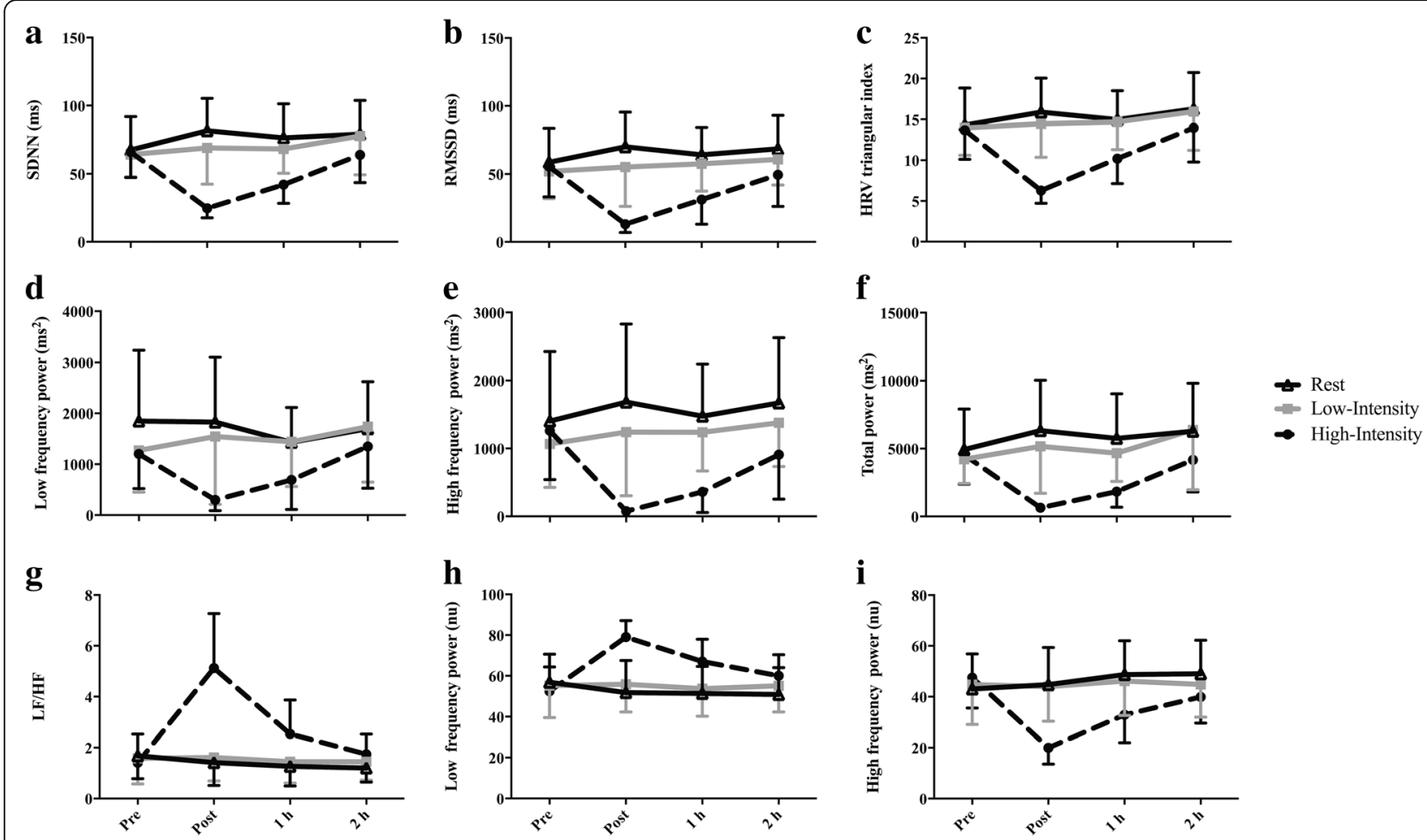

Fig. 1 Heart rate variability (HRV) in 15 males prior to and following rest, low-intensity, or high-intensity cycling: (a) SDNN: Standard deviation of NN intervals, (b) RMSSD: root mean square of successive intervals, (c) HRV triangular index, (d) Low frequency (LF) power, (e) High frequency (HF) power, (f) Total power, (g) LF/HF, (h) LF power normalized units (nu), (i) HF power nu. A summary of significant differences can be found in Additional files 1 and 2

Mean baseline $\mathrm{FEV}_{1}$ was $4.31(0.76) \mathrm{L}, \mathrm{FVC}$ was 5.48 (1.13) $\mathrm{L}, \mathrm{FEV}_{1} / \mathrm{FVC}$ was 0.79 (0.07), $\mathrm{FEF}_{25-75} 4.00(0.91)$ $\mathrm{L} / \mathrm{s}$ and PEFR was $9.79(1.31) \mathrm{L} / \mathrm{s}$. There was a significant interaction effect for PEFR (exposure-by-intensity: $p=0.036$, Fig. 3a; intensity-by-time: $p=0.04$, Fig. 3b). An exposure-by-intensity interaction suggested that during high-intensity exercise in FA, PEFR was significantly greater than low-intensity exercise (Fig. 3a. $p=0.010$; 9.93 (1.30) $\mathrm{L} / \mathrm{s}$ vs. $9.52(1.08) \mathrm{L} / \mathrm{s})$ and rest $(p=0.017 ; 9.93$ (1.30) L/s vs. $9.65(1.24) \mathrm{L} / \mathrm{s})$. However, this relationship did not occur with DE. An intensity-by-time interaction showed that immediately following high-intensity exercise PEFR was significantly greater than following low-intensity exercise (Fig. 3b. $p=0.011 ; 9.95(1.30) \mathrm{L} / \mathrm{s}$ vs. $9.52(1.11) \mathrm{L} / \mathrm{s})$ and rest $(p=0.017 ; 9.95(1.30) \mathrm{L} / \mathrm{s}$ vs. $9.57(1.31) \mathrm{L} / \mathrm{s})$. There were no other main or interaction effects for $\mathrm{FEV}^{1}$, $\mathrm{FVC}$ or $\mathrm{FEF}^{25-75}$.

There was a significant interaction effect (intensity-by-time: $p<0.001$, Fig. 4) for plasma norepinephrine but DE exposure did not modify this response. One hour post low-intensity exercise norepinephrine levels were significantly greater than prior to exercise $(p=0.015 ; 404.75$ (34.43) $\mathrm{pg} \bullet \mathrm{mL}^{-1}$ vs. $\left.342.59(25.24) \mathrm{pg} \cdot \mathrm{mL}^{-1}\right)$. Prior to high intensity exercise norepinephrine was significantly less than immediately post $\left(p=0.003 ; 366.69(29.81) \mathrm{pg} \cdot \mathrm{mL}^{-1}\right.$ vs. $\left.544.23(39.25) \mathrm{pg} \cdot \mathrm{mL}^{-1}\right)$ and $1 \mathrm{~h}$ post exercise $\left(p=0.002 ; 366.69(29.81) \mathrm{pg} \cdot \mathrm{mL}^{-1}\right.$ vs. $504.16(31.49)$ $\left.\mathrm{pg} \cdot \mathrm{mL}^{-1}\right)$. The elevation seen immediately post and $1 \mathrm{~h}$ post high-intensity exercise meant that plasma norepinephrine levels at these time points were significantly greater than $2 \mathrm{~h}$ post exercise $(p=0.007$; post vs. $2 \mathrm{~h}: 544.23$ (39.25) $\mathrm{pg} \cdot \mathrm{mL}^{-1}$ vs. $421.71(25.13) \mathrm{pg} \cdot \mathrm{mL}^{-1} ; p=0.007$; $1 \mathrm{~h}$ vs. $2 \mathrm{~h}: 504.16(31.49) \mathrm{pg} \cdot \mathrm{mL}^{-1}$ vs. $421.71(25.13)$ $\left.\mathrm{pg} \cdot \mathrm{mL}^{-1}\right)$. Norepinephrine was significantly greater immediately post high-intensity exercise compared to immediately post rest $\left(\mathrm{p}=0.002 ; 544.23(39.25) \mathrm{pg} \cdot \mathrm{mL}^{-1}\right.$ vs. $\left.370.10(25.83) \mathrm{pg} \cdot \mathrm{mL}^{-1}\right)$ and low-intensity exercise $\left(p<0.001 ; 544.23(39.25) \mathrm{pg} \cdot \mathrm{mL}^{-1}\right.$ vs. $363.81(26.31)$ $\left.\mathrm{pg} \bullet \mathrm{mL}^{-1}\right)$. Similarly, norepinephrine was significantly greater $1 \mathrm{~h}$ following high-intensity exercise compared to 1 h post rest $\left(p=0.004 ; 504.16(31.49) \mathrm{pg} \cdot \mathrm{mL}^{-1}\right.$ vs. 375.17 (27.37) $\left.\mathrm{pg} \bullet \mathrm{mL}^{-1}\right)$ and low-intensity exercise $(p=0.025$; $504.16(31.49) \mathrm{pg} \cdot \mathrm{mL}^{-1}$ vs. $\left.404.76(34.43) \mathrm{pg} \cdot \mathrm{mL}^{-1}\right)$.

There was a significant interaction effect (condition-by-time: $p=0.021$, Fig. 5) for throat/chest symptoms. Immediately following exposure to FA, symptoms for the throat/chest were significantly greater than symptoms prior to exposure $(p=0.005 ; 1.06(0.24)$ vs. 0.24 $(0.07)), 1 \mathrm{~h}$ post exposure $(p=0.032 ; 1.06(0.24)$ vs. 0.22 , $(0.08))$ and $2 \mathrm{~h}$ post exposure $(p=0.020 ; 1.06(0.24)$ vs. $0.24(0.08))$. Similarly, immediately following exposure to $\mathrm{DE}$, symptoms for the throat/chest were significantly 

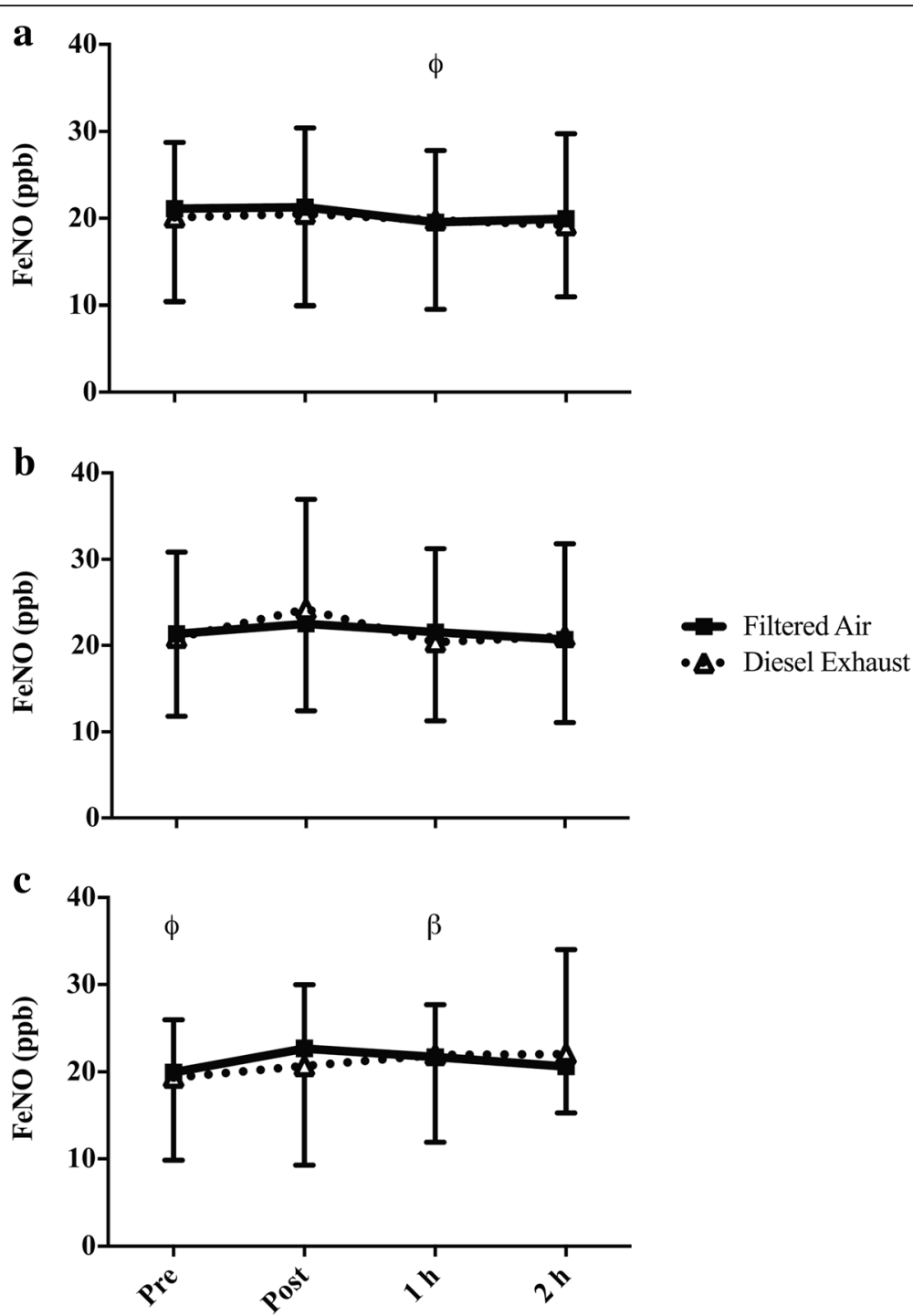

Fig. 2 FeNO prior to and following a rest, $\mathbf{b}$ low-intensity, or $\mathbf{c}$ high-intensity cycling in FA or DE. Significance is set at $p<0.05$. $\beta=$ significantly greater than pre-exercise in the corresponding exposure, occurs only in DE (diesel exhaust) only; $\varphi=$ significantly less than post in the corresponding exposure (FA (filtered air) only)

greater than symptoms prior to exposure $(p<0.001 ; 1.74$ $(0.28)$ vs. $0.24(0.07)), 1 \mathrm{~h}$ post exposure $(p<0.001 ; 1.74$ $(0.28)$ vs. $0.37(0.10))$ and $2 \mathrm{~h}$ post exposure $(p=0.001$; $1.74(0.28)$ vs. $0.37(0.12))$. However, the increase in symptoms immediately following $\mathrm{DE}$ was significantly greater following FA ( $p=0.024 ; 1.74(0.28)$ vs. $1.06(0.24))$.

There was also a significant intensity-by-time interaction for eye symptoms $(p=0.042)$, nasal symptoms $(p=0.031)$, throat/chest symptoms $(p<0.001)$ and other symptoms $(p<0.001)$. Post hoc comparisons for eye symptoms did not reveal significant differences. See Table 1 for Post hoc comparisons for the intensity-by-time interaction for all categories of symptoms. The dataset supporting the conclusions of this can be made available upon request.

\section{Discussion}

This is the first study to determine the pulmonary and autonomic nervous system effects of (DE) exposure with exercise of varying intensities. We found that following $30 \mathrm{~min}$ of exercise pulmonary function, FeNO, HRV, or plasma norepinephrine were not significantly different between low- and high-intensity exercise in DE. However, exposure to DE did exacerbate throat and chest symptoms to a significantly greater degree than following FA.

Particulate matter exposure causes oxidative stress, and increases bronchial responsiveness, airway resistance, and airway inflammatory cells [3, 4]. Following high-intensity exercise in FA and DE (immediately post in FA and $1 \mathrm{~h}$ post in DE) FeNO, which is a surrogate measure of airway 


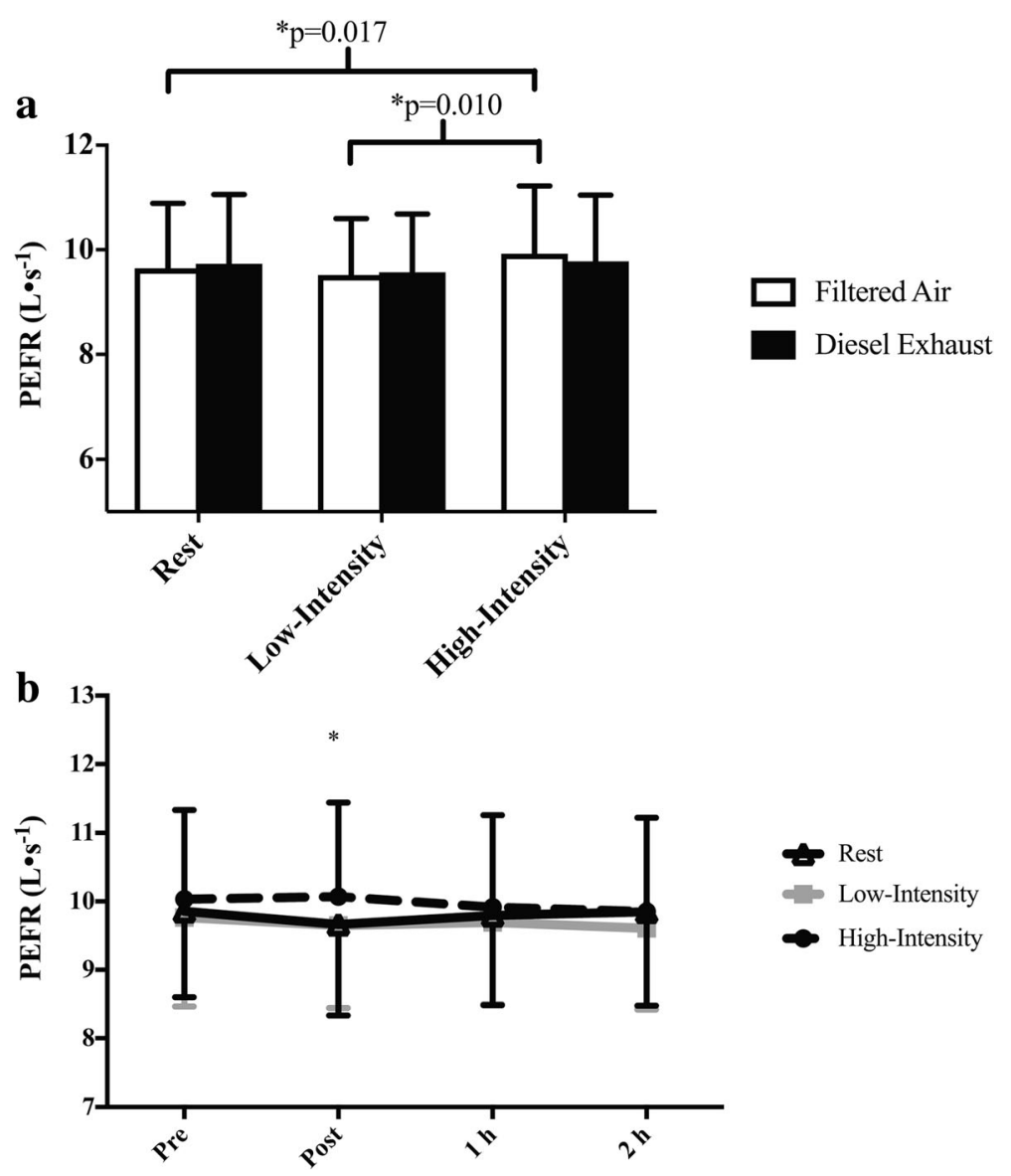

Fig. 3 a Exposure-by-intensity interaction and $\mathbf{b}$ intensity-by-time interaction for PEFR. Significance is set at $p<0.05$. For the exposure-byintensity interaction data is collapsed across all time points and for the intensity-by-time interaction data is collapsed across both exposure conditions. * Low-intensity $(p=0.011)$ and rest $(p=0.017)$ are significantly less than high-intensity exercise at the post-exercise time point

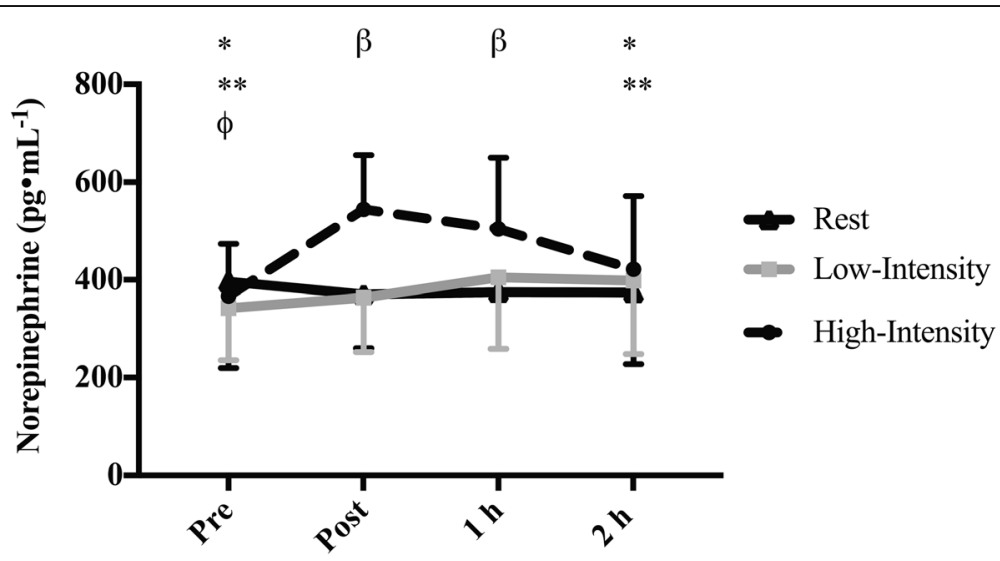

Fig. 4 Plasma norepinephrine in 18 males prior to and following rest, low-intensity cycling and high-intensity cycling. Significance is set at $p<0.05$. For the intensity-by-time interaction data is collapsed across both exposure conditions. * Significantly less than post in the corresponding exercise intensity (high-intensity only). ${ }^{*}$ Significantly less than $1 \mathrm{~h}$ in the corresponding exercise intensity (high-intensity only). $\beta$ Significantly greater in highintensity compared to low-intensity and rest. $\Phi$ Significantly less than $1 \mathrm{~h}$ in the corresponding exercise intensity (low-intensity only) 


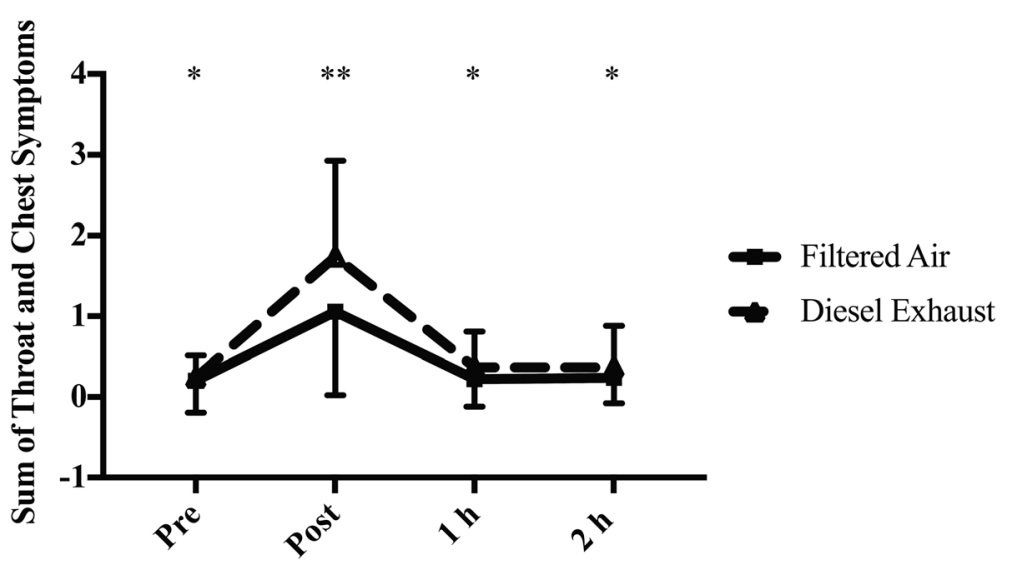

Fig. 5 Sum of Throat and Chest symptoms prior to and following FA and DE. Significance set at $0<0.05$. FA: Filtered air, DE: Diesel exhaust. *Significantly less than post in the corresponding exposure (occurs in both DE and FA). ${ }^{*}$ DE significantly greater than FA at the same time point

inflammation, was significantly greater than compared to baseline. The increase in FeNO was similar between DE and FA, suggesting that DE did not magnify the response. Therefore, these data suggest that in healthy individuals, exercise in DE does not potentiate pulmonary inflammation as measured by FeNO; however, we cannot discount

Table 1 Mean (SD) for subjective symptoms in 18 recreationally active males prior to and following exercise or rest

\begin{tabular}{|c|c|c|c|}
\hline & Rest & Low-Intensity & High-Intensity \\
\hline & \multicolumn{3}{|c|}{ Mean (SD) [95\% Cl] } \\
\hline \multicolumn{4}{|c|}{ Nasal Symptoms } \\
\hline Pre & $0.33(0.45)$ & $0.22(0.43)^{*}$ & $0.44(0.48)$ \\
\hline Post & $0.42(0.65)^{* *}$ & $0.64(0.76)^{*}$ & $1.08(1.06)$ \\
\hline $1 \mathrm{~h}$ post & $0.25(0.39)$ & $0.17(0.30)$ & $0.39(0.63)^{*}$ \\
\hline $2 \mathrm{~h}$ post & $0.19(0.31)$ & $0.08(0.26) *$ & $0.17(0.34)^{*}$ \\
\hline \multicolumn{4}{|c|}{ Throat/Chest Symptoms } \\
\hline Pre & $0.28(0.39)^{*}$ & $0.25(0.43) *$ & $0.14(0.33) *$ \\
\hline Post & $0.81(0.79)^{* *}$ & $0.83(0.66)^{* *}$ & $2.56(2.07)$ \\
\hline $1 \mathrm{~h}$ post & $0.39(0.47)$ & $0.17(0.34) * \Phi$ & $0.33(0.42) *$ \\
\hline $2 \mathrm{~h}$ post & $0.33(0.42)^{*}$ & $0.31(0.49) *$ & $0.28(0.39) *$ \\
\hline \multicolumn{4}{|c|}{ Eye Symptoms } \\
\hline Pre & $0.36(0.17)$ & $0.19(0.11)$ & $0.11(0.09)$ \\
\hline Post & $0.17(0.07)$ & $0.22(0.08)$ & $0.50(0.17)$ \\
\hline $1 \mathrm{~h}$ post & $0.14(0.08)$ & $0.11(0.09)$ & $0.14(0.07)$ \\
\hline $2 \mathrm{~h}$ post & $0.08(0.06)$ & $0.06(0.04)$ & $0.11(0.07)$ \\
\hline \multicolumn{4}{|c|}{ Other Symptoms } \\
\hline Pre & $0.19(0.07)$ & $0.22(0.09)$ & $0.14(0.07)^{*}$ \\
\hline Post & $0.47(0.17)^{* *}$ & $0.67(0.17)^{* * *}$ & $2.11(0.34)$ \\
\hline $1 \mathrm{~h}$ post & $0.14(0.07) * *$ & $0.31(0.11)$ & $0.67(0.23)^{*}$ \\
\hline $2 \mathrm{~h}$ post & $0.11(0.07) * *$ & $0.14(0.05)$ & $0.31(0.09)^{*}$ \\
\hline
\end{tabular}

*significantly less than post in the corresponding intensity, $p<0.05$

**significantly less than high-intensity at the corresponding time point, $p<0.05$

$\Phi$ significantly less than rest at the corresponding time point, $p<0.05$ that other markers of pulmonary inflammation, such as eosinophils in sputum, have been affected. The lack of a DE effect contradicts our initial hypothesis that DE exposure would increase the amount of pulmonary inflammation post-exercise. Our findings are similar to others showing that in healthy individuals, acute exercise/ physical activity in a high pollution/high traffic environment is not associated with elevated FeNO [19, 34, 35]. Rundell et al. assessed the FeNO response to $30 \mathrm{~min}$ of cycling at 85-95\% of maximum heart rate while Jacobs et al. assessed the FeNO response to $20 \mathrm{~min}$ of cycling at $74 \%$ of maximum heart rate $[19,34]$. The intensities used by Rundell et al. and Jacobs et al. are similar to the high- and low-intensity trials in the current study $[19,34]$ and further corroborate our findings that exercise of varying intensities with exposure to air pollution does not affect FeNO. In this study we did not see acute changes in FeNO with exposure to DE but it is possible that repeated exposure during exercise/ physical activity is necessary to increase FeNO. For example, Bos et al. [36] found that individuals who aerobically trained in a polluted urban environment had significantly elevated FeNO compared to those aerobically training in a less polluted rural environment. The absence of a DE and FA difference could also be due to post-exercise measurements occurring over too short of a time frame or that that FeNO may not be a stable or sensitive enough indicator of pulmonary inflammation in healthy individuals.

Our finding suggesting that high-intensity exercise increases FeNO, contrasts with work done by Verges et al. who examined FeNO following 25 min of incremental exercise (two $10 \mathrm{~min}$ bouts at 46 and $60 \%$ of peak power, followed by five min at $90 \%$ of peak power) [37]. Immediately following exercise, Verges et al. found that FeNO significantly decreased [37]. Similarly, Evjenth et al. tested FeNO following an $8 \mathrm{~min}$ incremental test that reached 95\% maximum heart rate [2] and found that immediately 
following and $30 \mathrm{~min}$ following exercise, FeNO levels were significantly reduced [2]. Our results may be in opposition to others $[2,37]$ due to the timeframe of sampling. In the study by Verges et al., FeNO levels were returning towards baseline $15 \mathrm{~min}$ following exercise [37]. The measurement of post-exercise FeNO in the current study occurred following a number of other physiological measures, which meant that the post-exercise FeNO measurement could have been measured up to $40 \mathrm{~min}$ post-exercise. Therefore, an immediate post-exercise reduction in FeNO could have been missed in the current study. As exercise duration was different between the current study and others [2,37], it is also possible that a different FeNO response was elicited.

In susceptible populations, PM-induced physiological changes such as oxidative stress, bronchial hyperresponsiveness, and inflammation $[3,4]$ can result in impaired lung function [38]. Within the current study, we found that in FA, PEFR was significantly greater following high-intensity exercise compared to rest. In DE, these differences did not occur, leading to a trend for lower PEFR in DE compared to FA. As the FA vs. DE differences were not significant, and there were no effects of exposure on other parameters of pulmonary function, one cannot conclude from this study that DE exposure during exercise affects pulmonary function or that exercise intensity magnifies this response. Our findings are similar to those of others who found no associations between exposure to air pollution/PM and pulmonary function following exercise or physical activity in urban areas [18, 20, 35], and found that physical activity reduced PM associated decrements in aspects of lung function such as PEFR [6].

Immediately following DE exposure, throat and chest symptoms were 0.68 points higher on a 5 -point scale compared to FA. Since the DE condition had such a high concentration of $\mathrm{PM}_{2.5}$, these findings are not surprising. It is interesting that in this healthy cohort, the participants noticed more symptoms, yet the objective measures of lung function and inflammation were not impacted. While, DE exposure contains a mixture of particulate matter and gaseous pollutants, it is possible that we did not observe differences in lung function and inflammation as the mixture within the current study may differ from ambient conditions. Additionally, we may not have observed significant differences based on the marker of pulmonary inflammation chosen. FeNO is a surrogate measure of eosinophilic airway inflammation and thus we cannot discount that other aspects of airway inflammation were impacted. Also, we cannot disregard that exercise duration, the time course of post exercise measures and the fitness level or health status of our participants may have led to non-significant findings. Finally, the sample size for the current study was calculated based on a minimal detectable difference in FeNO; therefore, it is possible that other outcomes measures were not adequately statistically powered.

One of the other potential pathways in which PM exposure causes cardiovascular effects is through an increase in sympathetic nervous system activity and a decrease in parasympathetic nervous system activity demonstrating a disruption in cardiac autonomic control [39]. Contrary to our hypothesis, our research demonstrated that HRV is not impacted by a controlled exposure to DE. This finding is in accordance with other controlled experimental diesel exposure studies [40, 41]. However, some epidemiological research suggests that as $\mathrm{PM}_{2.5}[42]$ or $\mathrm{PM}_{10}[43,44]$ concentrations increase, HRV is impaired (as demonstrated by reductions in SDNN and RMSSD), yet there is still is a lack of consensus on the magnitude, direction, and existence of an effect; as is demonstrated by some studies finding a significant but positive association between PM and SDNN [45] and others finding no association between PM and indices of HRV [46]. Despite inconsistencies in the literature, it appears that controlled diesel exposure studies demonstrate a lack of an effect on HRV, while observational and epidemiological studies are generally conflicting. This discrepancy could be related to three factors. DE does not contain metals found in atmospheric air pollution such as nickel, lead, arsenic and cadmium. These metals are thought to play a key role in the autonomic nervous system response to air pollution [47]. A laboratory environment allows researchers control of confounding factors and in this context does not contain extraneous stressors, such as noise and traffic, which may affect HRV. Finally, it is possible that there could be a more long-term association between air pollution and HRV that is not captured in the laboratory studies.

As highlighted, some PM exposure can cause an increase in sympathetic nervous system activity and a decrease in parasympathetic nervous system activity [39]. As both the adrenal medulla and sympathetic nerve endings produce norepinephrine, it is no surprise that production of norepinephrine will increase in response to sympathetic stimulation and potentially PM exposure. Norepinephrine is produced by sympathetic nerve endings and plays an important role in the pulmonary inflammatory response to PM exposure [48]. Therefore we reasoned that any changes in HRV and FeNO would be accompanied by changes in norepinephrine. We found that plasma norepinephrine levels were significantly increased following high intensity exercise, but there was no difference in response between DE and FA. These findings follow a similar pattern to the changes in FeNO and HRV and are likely related to persistent sympathetic activation following exercise/physical activity. The lack of an effect of DE on norepinephrine is similar to other human studies [49], but contrasts with human studies 
animal studies that found exposure to concentrated ambient particles increases norepinephrine in urine [50] and the paraventricular nucleus of the hypothalamus [8]. As with the HRV findings, the absence of effect of DE on norepinephrine could be related to the constituents of the pollution exposure, the time course of the study, or the lack of extraneous stressors such as noise and traffic.

\section{Conclusions}

The current study assessed the acute pulmonary, autonomic nervous system and symptomatic effects to $30 \mathrm{~min}$ of rest, low-, and high-intensity cycling with DE exposure in healthy recreationally active males. We initially hypothesized that DE would impair pulmonary function, cause pulmonary inflammation, increase symptoms related to DE exposure and result in autonomic responses that would be magnified by exercise intensity; however, our results do not support these hypotheses. Based on the results of this study, healthy individuals may experience an increase in throat and chest symptoms with DE exposure but exercising in DE does not magnify these. Additionally, healthy individuals may not experience acute pulmonary and autonomic effects from exercising in DE. However, to substantiate this claim, more research is needed to determine the effects of different compositions of air pollution over longer time frames during exercise. Furthermore, these findings only apply to a healthy, active population; further work in clinical populations is necessary in order to understand the combined effects of air pollution and exercise in these groups.

\section{Additional files}

Additional file 1: Intensity-by-time interaction summary table for heart rate variability, summarizing significant differences $(p<0.05)$ at each intensity between time points. (DOCX $66 \mathrm{~kb}$ )

Additional file 2: Intensity-by-time interaction summary table for heart rate variability, summarizing significant differences $(p<0.05)$ at each time point between exercise intensities. (DOCX $72 \mathrm{~kb}$ )

\footnotetext{
Abbreviations

VO $_{2 \text { peak: }}$ Peak oxygen consumption; DE: Diesel exhaust; DPM: Diesel exhaust particulate matter; ELISA: Enzyme-linked immunosorbent assay; FA: Filtered air; $F_{F F}$ 25: Forced expiratory flow in the middle $50 \%$ of expiration; FeNO: Fraction of exhaled nitric oxide; $\mathrm{FEV}_{1}$ : Forced expiratory volume in $1 \mathrm{~s}$; FVC: Forced vital capacity; H: Hour(s); HF (nu): High frequency power in normalized units; HFP: High frequency power; HRV: Heart rate variability; LF (nu): Low frequency power in normalized units; LF/HF: Low frequency/high frequency ratio; LFP: Low frequency power; Min: Minutes;

NE: Norepinephrine; NN: Normal-to-normal interval; NO: Nitric oxide; $\mathrm{NO}_{2}$ : Nitrogen dioxide; PEFR: Peak expiratory flow rate; PM: Particulate matter; $\mathrm{PM}_{10}$ : Particulate matter with a mass median aerodynamic diameter less than $10 \mu \mathrm{m} ; \mathrm{PM}_{2.5}$ : Particulate matter with a mass median aerodynamic diameter less than $2.5 \mu \mathrm{m}$; PNC: Particle number concentration; RMSSD: Root mean square of successive intervals; SDNN: Standard deviation of normal-to-normal intervals; UFP: Ultrafine particulate matter
}

\section{Acknowledgements}

The authors would like to thank Jason Brandenburg, Tavinder Ark and Martha Smith for their assistance with data collection, study design and statistical analysis. The majority of this work was completed while Luisa Giles was affiliated with the Kinesiology department at UBC, Luisa Giles is currently affiliated with Douglas College.

\section{Funding}

The Canadian Academy of Sport and Exercise Medicine, Health Canada, the Fraser Basin Council BC Clean Air Research Fund (BC CLEAR) and the Natural Science and Engineering Research Council (NSERC).

\section{Availability of data and materials}

The datasets used and/or analysed during the current study are available from the corresponding author on reasonable request.

\section{Authors' contributions}

LVG: Conceived and design research, performed experiments, analyzed data, interpreted results of experiments, prepared figures, drafted manuscript, edited and revised manuscript, approved final version of manuscript and agreed to be accountable for all aspects of the work. CC: Conceived and design research, interpreted results of experiments, edited and revised manuscript, approved final version of manuscript and agreed to be accountable for all aspects of the work. MSK: Conceived and design research, analyzed data, interpreted results of experiments, edited and revised manuscript, approved final version of manuscript and agreed to be accountable for all aspects of the work.

Ethics approval and consent to participate

The Clinical Research Ethics Board at the University of British Columbia approved this study.

\section{Consent for publication}

NA

\section{Competing interests}

The authors declare that they have no competing interests.

\section{Publisher's Note}

Springer Nature remains neutral with regard to jurisdictional claims in published maps and institutional affiliations.

\section{Author details}

${ }^{1}$ Sport Science Department, Douglas College, 700 Royal Ave, New Westminster, BC V3M 5Z5, Canada. ${ }^{2}$ School of Kinesiology, University of British Columbia, Vancouver, British Columbia, Canada. ${ }^{3}$ Department of Medicine, University of British Columbia, Vancouver, British Columbia, Canada. ${ }^{4}$ Institute for Heart and Lung Health, Vancouver, British Columbia, Canada. ${ }^{5}$ School of Population and Public Health, University of British Columbia, Vancouver, British Columbia, Canada. ${ }^{6}$ Division of Sports Medicine, University of British Columbia, Vancouver, British Columbia, Canada. ${ }^{7}$ Department of Biomedical Physiology and Kinesiology, Simon Fraser University, Burnaby, British Columbia, Canada.

Received: 29 June 2018 Accepted: 29 November 2018 Published online: 13 December 2018

\section{References}

1. Giles LV, Carlsten C, Koehle MS. The effect of pre-exercise diesel exhaust exposure on cycling performance and cardio-respiratory variables. Inhal Toxicol. 2012;24:783-9.

2. Evjenth B, Hansen TE, Holt J. Exhaled nitric oxide decreases during exercise in non-asthmatic children. Clin Respir J. 2013;7:121-7.

3. Holgate ST, Sandstrom T, Frew AJ, Stenfors N, Nordenhall C, Salvi S, Blomberg A, Helleday R, Soderberg M. Health effects of acute exposure to air pollution. Part l: healthy and asthmatic subjects exposed to diesel exhaust. Res Rep Health Eff Inst. 2003:1-30 discussion 51-67.

4. Kelly FJ. Oxidative stress: its role in air pollution and adverse health effects. Occup Environ Med. 2003;60:612-6. 
5. Goss CH, Newsom SA, Schildcrout JS, Sheppard L, Kaufman JD. Effect of ambient air pollution on pulmonary exacerbations and lung function in cystic fibrosis. Am J Respir Crit Care Med. 2004;169:816-21.

6. Matt F, Cole-Hunter T, Donaire-Gonzalez D, Kubesch N, Martínez D, Carrasco-Turigas G, Nieuwenhuijsen M. Acute respiratory response to trafficrelated air pollution during physical activity performance. Environ Int. 2016; 97:45-55.

7. Brook RD, Rajagopalan S, Pope CA 3rd, Brook JR, Bhatnagar A, Diez-Roux AV, Holguin F, Hong Y, Luepker RV, Mittleman MA, et al. Particulate matter air pollution and cardiovascular disease: an update to the scientific statement from the American Heart Association. Circulation. 2010;121:2331-78.

8. Balasubramanian P, Sirivelu MP, Weiss KA, Wagner JG, Harkema JR, Morishita M, Mohankumar PS, Mohankumar SM. Differential effects of inhalation exposure to PM2.5 on hypothalamic monoamines and corticotrophin releasing hormone in lean and obese rats. Neurotoxicology. 2013;36:106-11.

9. Arai Y, Saul JP, Albrecht P, Hartley LH, Lilly LS, Cohen RJ, Colucci WS Modulation of cardiac autonomic activity during and immediately after exercise. Am J Phys. 1989;256:H132-41.

10. Kaikkonen P, Rusko H, Martinmaki K. Post-exercise heart rate variability of endurance athletes after different high-intensity exercise interventions. Scand J Med Sci Sports. 2008;18:511-9.

11. Casadei B, Cochrane S, Johnston J, Conway J, Sleight P. Pitfalls in the interpretation of spectral analysis of the heart rate variability during exercise in humans. Acta Physiol Scand. 1995;153:125-31.

12. Hautala AJ, Makikallio TH, Seppanen T, Huikuri HV, Tulppo MP. Short-term correlation properties of R-R interval dynamics at different exercise intensity levels. Clin Physiol Funct Imaging. 2003;23:215-23.

13. Perini $R$, Orizio $C$, Baselli $G$, Cerutti $S$, Veicsteinas $A$. The influence of exercise intensity on the power spectrum of heart rate variability. Eur J Appl Physiol Occup Physiol. 1990;61:143-8.

14. Pichon AP, de Bisschop C, Roulaud M, Denjean A, Papelier Y. Spectral analysis of heart rate variability during exercise in trained subjects. Med Sci Sports Exerc. 2004;36:1702-8.

15. Yamamoto $Y$, Hughson RL, Peterson JC. Autonomic control of heart rate during exercise studied by heart rate variability spectral analysis. J Appl Physiol. 1991;71:1136-42

16. Krishnan RM, Sullivan JH, Carlsten C, Wilkerson HW, Beyer RP, Bammler T, Farin F, Peretz A, Kaufman JD. A randomized cross-over study of inhalation of diesel exhaust, hematological indices, and endothelial markers in humans. Part Fibre Toxicol. 2013;10:7.

17. Terziotti P, Schena F, Gulli G, Cevese A. Post-exercise recovery of autonomic cardiovascular control: a study by spectrum and cross-spectrum analysis in humans. Eur J Appl Physiol. 2001;84:187-94.

18. Jarjour S, Jerrett M, Westerdahl D, de Nazelle A, Hanning C, Daly L, Lipsitt J, Balmes J. Cyclist route choice, traffic-related air pollution, and lung function: a scripted exposure study. Environ Health. 2013;12:14.

19. Rundell KW, Slee JB, Caviston R, Hollenbach AM. Decreased lung function after inhalation of ultrafine and fine particulate matter during exercise is related to decreased total nitrate in exhaled breath condensate. Inhal Toxicol. 2008;20:1-9.

20. Strak M, Boogaard H, Meliefste K, Oldenwening M, Zuurbier M, Brunekreef B, Hoek G. Respiratory health effects of ultrafine and fine particle exposure in cyclists. Occup Environ Med. 2010;67:118-24.

21. Daigle CC, Chalupa DC, Gibb FR, Morrow PE, Oberdorster G, Utell MJ, Frampton MW. Ultrafine particle deposition in humans during rest and exercise. Inhal Toxicol. 2003;15:539-52.

22. Finlay $\mathrm{WH}$. Mechanics of inhaled pharmaceutical aerosols - an introduction: Elsevier; 2001.

23. Heyder J. Deposition of inhaled particles in the human respiratory tract and consequences for regional targeting in respiratory drug delivery. Proc Am Thorac Soc. 2004;1:315-20.

24. Scichilone N, Battaglia S, Braido F, Collura A, Menoni S, Arrigo R, Benfante A, Bellia V. Exhaled nitric oxide is associated with cyclic changes in sexual hormones. Pulm Pharmacol Ther. 2013;26:644-8.

25. Barath S, Mills NL, Adelroth E, Olin AC, Blomberg A. Diesel exhaust but not ozone increases fraction of exhaled nitric oxide in a randomized controlled experimental exposure study of healthy human subjects. Environ Health 2013;12:36.

26. Giles LV, Brandenburg JP, Carlsten C, Koehle MS. Physiological responses to diesel exhaust exposure are modified by cycling intensity. Med Sci Sports Exerc. 2014;46:1999-2006.
27. Giles LV, Tebbutt SJ, Carlsten C, Koehle MS. The effect of low and highintensity cycling in diesel exhaust on flow-mediated dilation, circulating NOx, endothelin-1 and blood pressure. PLoS One. 2018;13:e0192419.

28. Carlsten C, Oron AP, Curtiss H, Jarvis S, Daniell W, Kaufman JD. Symptoms in response to controlled diesel exhaust more closely reflect exposure perception than true exposure. PLoS One. 2013;8:e83573.

29. Patrician PA. Multiple imputation for missing data. Res Nurs Health. 2002;25:76-84.

30. Dweik RA, Boggs PB, Erzurum SC, Irvin CG, Leigh MW, Lundberg JO, Olin AC, Plummer AL, Taylor DR. An official ATS clinical practice guideline: interpretation of exhaled nitric oxide levels (FENO) for clinical applications. Am J Respir Crit Care Med. 2011;184:602-15.

31. Miller MR, Crapo R, Hankinson J, Brusasco V, Burgos F, Casaburi R, Coates A, Enright $P$, van der Grinten CP, Gustafsson P, et al. General considerations for lung function testing. Eur Respir J. 2005:26:153-61.

32. Goodman C, Rogers GG, Vermaak H, Goodman MR. Biochemical responses during recovery from maximal and submaximal swimming exercise. Eur J Appl Physiol Occup Physiol. 1985;54:436-41

33. Birger N, Gould T, Stewart J, Miller MR, Larson T, Carlsten C. The air pollution exposure laboratory (APEL) for controlled human exposure to diesel exhaust and other inhalants: characterization and comparison to existing facilities. Inhal Toxicol. 2011;23:219-25.

34. Jacobs L, Nawrot TS, de Geus B, Meeusen R, Degraeuwe B, Bernard A, Sughis M, Nemery B, Panis LI. Subclinical responses in healthy cyclists briefly exposed to traffic-related air pollution: an intervention study. Environ Health. 2010;9:64

35. Kubesch NJ, de Nazelle A, Westerdahl D, Martinez D, Carrasco-Turigas G, Bouso L, Guerra S, Nieuwenhuijsen MJ. Respiratory and inflammatory responses to short-term exposure to traffic-related air pollution with and without moderate physical activity. Occup Environ Med. 2015;72:284-93.

36. Bos I, De Boever P, Vanparijs J, Pattyn N, Panis LI, Meeusen R. Subclinical effects of aerobic training in urban environment. Med Sci Sports Exerc. 2013;45:439-47.

37. Verges S, Flore P, Favre-Juvin A, Levy P, Wuyam B. Exhaled nitric oxide during normoxic and hypoxic exercise in endurance athletes. Acta Physiol Scand. 2005;185:123-31.

38. Barraza-Villarreal A, Sunyer J, Hernandez-Cadena L, Escamilla-Nunez MC, Sienra-Monge JJ, Ramirez-Aguilar M, Cortez-Lugo M, Holguin F, DiazSanchez D, Olin AC, Romieu I. Air pollution, airway inflammation, and lung function in a cohort study of Mexico City schoolchildren. Environ Health Perspect. 2008;116:832-8

39. Pope CA 3rd, Dockery DW. Health effects of fine particulate air pollution: lines that connect. J Air Waste Manag Assoc. 2006;56:709-42.

40. Mills NL, Finlayson AE, Gonzalez MC, Tornqvist H, Barath S, Vink E, Goudie C, Langrish JP, Soderberg S, Boon NA, et al. Diesel exhaust inhalation does not affect heart rhythm or heart rate variability. Heart. 2011;97:544-50.

41. Peretz A, Kaufman JD, Trenga CA, Allen J, Carlsten C, Aulet MR, Adar SD, Sullivan $\mathrm{JH}$. Effects of diesel exhaust inhalation on heart rate variability in human volunteers. Environ Res. 2008;107:178-84.

42. Pieters $N$, Plusquin M, Cox B, Kicinski M, Vangronsveld J, Nawrot TS. An epidemiological appraisal of the association between heart rate variability and particulate air pollution: a meta-analysis. Heart. 2012;98:1127-35.

43. Pope CA 3rd, Dockery DW, Kanner RE, Villegas GM, Schwartz J. Oxygen saturation, pulse rate, and particulate air pollution: a daily time-series panel study. Am J Respir Crit Care Med. 1999;159:365-72.

44. Cole-Hunter T, de Nazelle A, Donaire-Gonzalez D, Kubesch N, CarrascoTurigas G, Matt F, Foraster M, Martinez T, Ambros A, Cirach M, et?al. Estimated effects of air pollution and space-time-activity on cardiopulmonary outcomes in healthy adults: a repeated measures study. Environ Int. 2018;111:247-59.

45. Riediker M, Cascio WE, Griggs TR, Herbst MC, Bromberg PA, Neas L, Williams RW, Devlin RB. Particulate matter exposure in cars is associated with cardiovascular effects in healthy young men. Am J Respir Crit Care Med. 2004;169:934-40.

46. Sullivan JH, Schreuder AB, Trenga CA, Liu SL, Larson TV, Koenig JQ, Kaufman JD. Association between short term exposure to fine particulate matter and heart rate variability in older subjects with and without heart disease. Thorax. 2005;60:462-6.

47. Jhun HJ, Kim H, Paek DM. The association between blood metal concentrations and heart rate variability: a cross-sectional study. Int Arch Occup Environ Health. 2005;78:243-7.

48. Chiarella SE, Soberanes S, Urich D, Morales-Nebreda L, Nigdelioglu R, Green D, Young JB, Gonzalez A, Rosario C, Misharin AV, et?al. Beta(2)-adrenergic 
agonists augment air pollution-induced IL-6 release and thrombosis. J Clin Invest. 2014;124:2935-46.

49. Peretz A, Sullivan JH, Leotta DF, Trenga CA, Sands FN, Allen J, Carlsten C, Wilkinson CW, Gill EA, Kaufman JD. Diesel exhaust inhalation elicits acute vasoconstriction in vivo. Environ Health Perspect. 2008;116:937-42.

50. Ying Z, Xu X, Bai Y, Zhong J, Chen M, Liang Y, Zhao J, Liu D, Morishita M, Sun $Q$, et al. Long-term exposure to concentrated ambient PM2.5 increases mouse blood pressure through abnormal activation of the sympathetic nervous system: a role for hypothalamic inflammation. Environ Health Perspect. 2014;122:79-86.

Ready to submit your research? Choose BMC and benefit from:

- fast, convenient online submission

- thorough peer review by experienced researchers in your field

- rapid publication on acceptance

- support for research data, including large and complex data types

- gold Open Access which fosters wider collaboration and increased citations

- maximum visibility for your research: over $100 \mathrm{M}$ website views per year

At $\mathrm{BMC}$, research is always in progress.

Learn more biomedcentral.com/submissions 